\title{
ELASTIC STABLE INTRAMEDULLARY NAILING OF FEMORAL AND TIBIAL SHAFT FRACTURES IN CHILDREN
}

Ramesh Prabu Ganesan¹, Srinivasan Anbu², Mathivanan Palaniappan³, Kalyanasundaram Kolundan', Kishore Kannan5, Subramaniankarunanithi6

${ }^{1}$ Assistant Professor, Department of Orthopaedics, KAPV Govt. Medical College/M G M Govt. Hospital, Tiruchirappalli. ${ }^{2}$ Associate Professor, Department of Orthopaedics, KAPV Govt. Medical College/M G M Govt. Hospital, Tiruchirappalli. ${ }^{3}$ Professor, Department of Orthopaedics, KAPV Govt. Medical College/M G M Govt. Hospital, Tiruchirappalli.

${ }^{4}$ Associate Professor, Department of Orthopaedics, KAPV Govt. Medical College/M G M Govt. Hospital, Tiruchirappalli. ${ }_{5}^{5}$ Assistant Professor, Department of Orthopaedics, KAPV Govt. Medical College/M G M Govt. Hospital, Tiruchirappalli. ${ }^{6}$ Assistant Professor, Department of Orthopaedics, KAPV Govt. Medical College/M G M Govt. Hospital, Tiruchirappalli.

\section{ABSTRACT}

\section{BACKGROUND AND OBJECTIVE}

Management of femoral and Tibial diaphyseal fractures in the age group of 5-15 years is still controversial between conservative and surgical methods. Compared with young children, this group of children have high risk of malunion and shortening when managed conservatively. Surgical methods are widely used in this age group of children with intramedullary fixation being increasingly preferred. Aim of this prospective study was designed to examine the outcome and complications of Elastic Stable Intramedullary Nailing (ESIN) in the treatment of paediatric fractures of shaft of femur and tibia between 5 to 15 years of age group.

\section{MATERIAL AND METHODS}

The study was conducted from 2009 to 2011 at Government Mohan Kumaramangalam Medical College Hospital, SALEM, included 20 patients who had sustained fracture shaft of femur and tibia and been treated with closed or open using Elastic Stable Intramedullary Nailing (ESIN). Among twenty children aged 5-15 years (16 cases were male and 4 cases were female), 10 cases had femur fractures and 10 cases had tibia fractures).

\section{RESULTS}

At the end of study, all the patients were evaluated for functional outcome according to Flynn's Titanium Elastic Nailing scoring system. All fractures were radiologically united at an average of 10.5 weeks in femur and 8.8 weeks in tibia fractures. In our study, out of 10 patients with shaft of femur fractures, excellent results in 8 patients, satisfactory in one patient and poor in one patient. Out of 10 patients with fracture shaft of tibia, 9 patients had excellent results. One patient had satisfactory result. Most of the complications were minor only.

\section{CONCLUSION}

Based on our studies and result, we conclude that Elastic Stable Intramedullary Nailing (ESIN) is an ideal choice of treatment for paediatric femur and tibia diaphyseal fractures of children between 5 and 15 years of age.

\section{KEYWORDS}

Tens, Elastic Nail, Femur Fracture, Tibia Fracture.

HOW TO CITE THIS ARTICLE: Ganesan RP, Anbu S, Palaniappan M, et al. Elastic stable intramedullary nailing of femoral and tibial shaft fractures in children. J. Evolution Med. Dent. Sci. 2016;5(71):5196-5201, DOI: 10.14260/jemds/2016/1178

\section{INTRODUCTION}

Incidence of Femoral shaft fractures is $1.6 \%$ of all bony injuries in children. The male-to-female ratio of femoral shaft fractures is 2.6:1 with bimodal distribution.1,2,3 The peak incidence occurs in early childhood and mid adolescence. The choice of treatment is based on the age of the child, severity of injury and associated injuries. Fractures in infants are usually managed by Pavlik Harness, immediate spica cast or traction followed by spica cast. Fractures in the age of 1 to 5 years is usually managed by closed reduction and spica cast

Financial or Other, Competing Interest: None.

Submission 22-07-2016, Peer Review 21-08-2016,

Acceptance 27-08-2016, Published 03-09-2016.

Corresponding Author:

Dr. Ramesh Prabu Ganesan,

No. 5, Aishwarya Apartment,

$B-3111^{\text {th }}$ Cross,

Thillai Nagar,

Trichy - 620018.

E-mail: grpsha@gmail.com

DOI: 10.14260/jemds/2016/1178 application, which is ideal treatment for most diaphyseal fractures for this age. But, the management of fractures in the age between 5 and 15 years is still controversial between conservative and surgical methods. Compared with young children, this group of children have high risk of malunion and shortening when managed conservatively.

Tibia fractures are the $3^{\text {rd }}$ most common long bone fractures in children (15\%) following the forearm and femur fractures. Approximately, 19 to 39\% occur in middle third of tibia.4,5,6 Most of the tibial diaphyseal fractures are managed conservatively. The available surgical methods for treating diaphyseal fractures of tibia are external fixator application, flexible intramedullary nailing and rigid intramedullary locking nail.

The above-mentioned procedures have certain complications like pin tract infection, refractures after external fixation, osteonecrosis with solid nails and high infection rate due to extensive dissection and periosteum stripping in plate fixation. 
Over the past few years, there has been a marked increase in the use of intramedullary fixation in the management of fractures of long bones in children. The use of titanium elastic nails allowed greater elasticity than was available in the steel nails of the Ender system.

ESIN is considered as the treatment of choice for femur and tibia shaft fractures in children aged 5-15 years. Elastic Stable Intramedullary Nailing (ESIN) is variously known as Flexible nailing/Titanium Elastic Nailing (TEN). ESIN is the Ideal choice for is transverse, short oblique, diaphyseal fracture with or without comminution.

\section{Principle and Biomechanics}

The flexible nail is initially bent or curved (plastically deformed). During intramedullary insertion, which is typically retrograde in the femur and antegrade in the tibia, the relatively straight medullary canal (compared with the deformed nail) forces the curved nail to straighten within the bone. This elastic deformation creates a bending moment within the long bone, which will tend to angulate the fracture site in the direction and the plane of the concavity of the curved nail as the nail tends to return to its initial curved state.

This moment is counteracted by a second nail of same diameter and curve, which balances the first nail with an equal, but opposite moment.

The two intramedullary nails act complimentarily to stabilise the fracture. This biological fixation is not rigid, but sufficiently stable against angular, torsional and translational deforming forces and is associated with early formation of exuberant callus. This is called as elastic stability. ${ }^{7}$

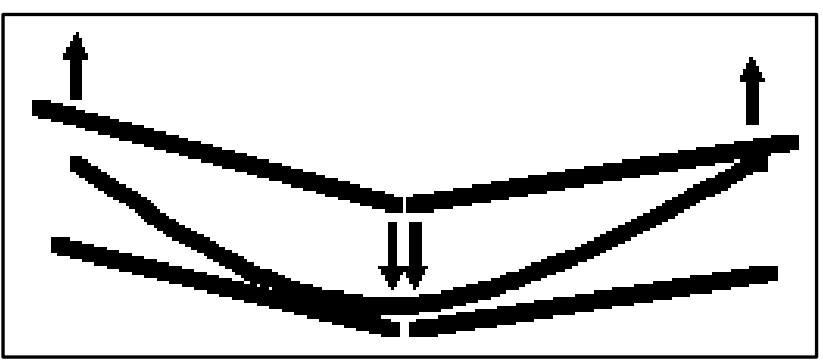

Fig.1: Biomechanics of Pre-Bent Elastic Nail - After One Nail Insertion

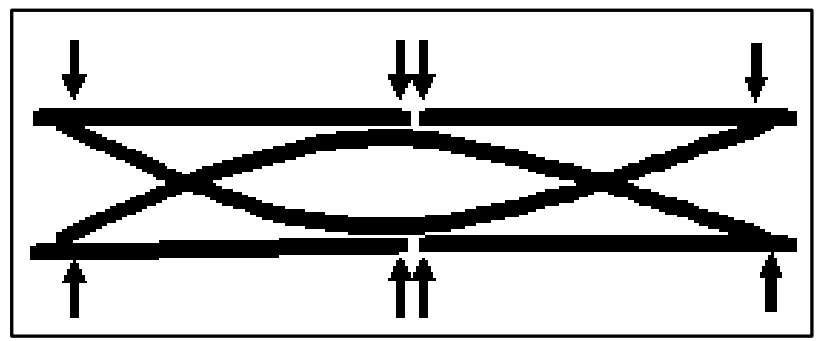

Fig. 2: After Two Nail Insertion Fracture Angulation Corrected by Elasticity

Two prebent elastic nails when inserted in opposite directions provide elastic stability.

The biomechanical principle of ESIN (Elastic Stable Intramedullary Nailing) is based on the symmetrical bracing action of two prebent elastic nails inserted into the metaphyseal region each of which bears against the inner bone at three points. This produces the following four properties: flexural, translational, axial and rotational stability. All the four properties are essential for achieving optimal results. The elasticity of titanium nail promotes callus formation at fracture site by limiting stress shielding. ${ }^{8,9}$

\section{MATERIALS AND METHODS}

The study was conducted from May 2009 to November 2011 at Government Mohan Kumaramangalam Medical College Hospital, Salem. The study included 20 patients who had sustained fracture shaft of femur and tibia and been treated with closed or open flexible intramedullary nail using Elastic Stable Intramedullary Nailing.

We have analysed the results with the maximum followup of 24 months and minimum followup of 5 months with an average of 14.5 months. This study was approved by the Ethical Committee of Government Medical College, Salem.

Among 20 children, male children (80\%) were predominant with male-to-female ratio $4: 1$. Out of the 20 patients , 16 of them had fractures due to road traffic accident, 3 falls from height and sports injury in 1 (one) patient. In our series, RTA was the predominant cause of injury.

The fracture pattern was classified using the classification of the AO/ASIF (Association for Osteosynthesis/Association for the Study of Internal Fixation).

\section{SURGICAL TECHNIQUE}

\section{Femur Fracture}

With the patient lying supine on a standard fracture table and under fluoroscopic control, closed fracture reduction was performed as the first step of the procedure either by manual traction or by using the nail as a joystick. Two nails were used. Nail diameter should measure $40 \%$ of the narrowest diameter of the diaphysis. Nails should be contoured with a long gentle bend such that the apex of the convexity will be at the level of the fracture.

Usually, entry point of the nail is selected on medial and lateral aspect of flare of femoral condyle of thigh. A 1 to $2 \mathrm{~cm}$ incision was made on the either side of the distal thigh just above the superior pole of the patella. Under image intensifier control, entry hole made on lateral cortex $2-2.5 \mathrm{~cm}$ above distal femoral physis by using a curved bone owl. Both the prebent nails are inserted through the entry points under image intensifier control, one nail after another and advanced up to fracture site. Fracture is reduced, aligned by manipulation (or) using radiolucent " $F$ " tool. Using image intensifier, the reduction was checked and the first nail was advanced across the fracture site. The nail was advanced 2 $\mathrm{cm}$ into the proximal fragment and rotated. Second nail was further advanced across the fracture site. The first nail should not be advanced too far as it may cause shifting of the fragments and make difficulty in passing second nail.

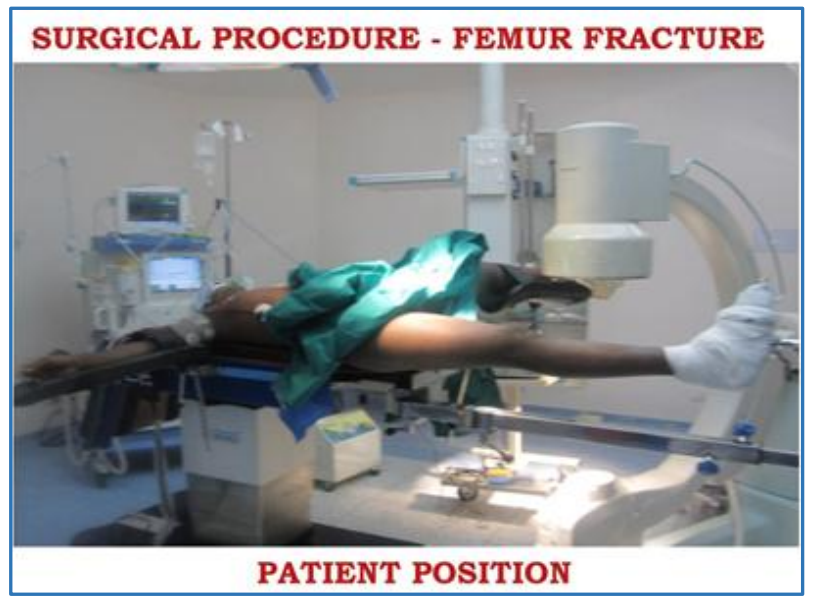

Fig.3: Surgical Procedure - Patient Position - Femur Fracture 

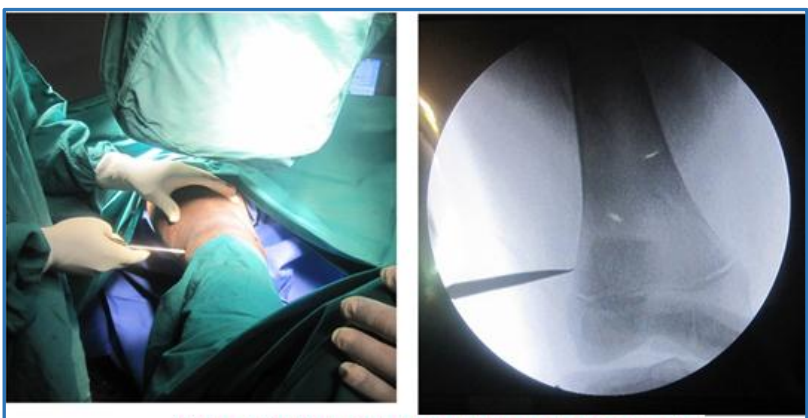

NAIL ENTRY POINT ON LATERAL CORTEX

Fig. 4: Nail Entry Point - Lateral Cortex of Femur

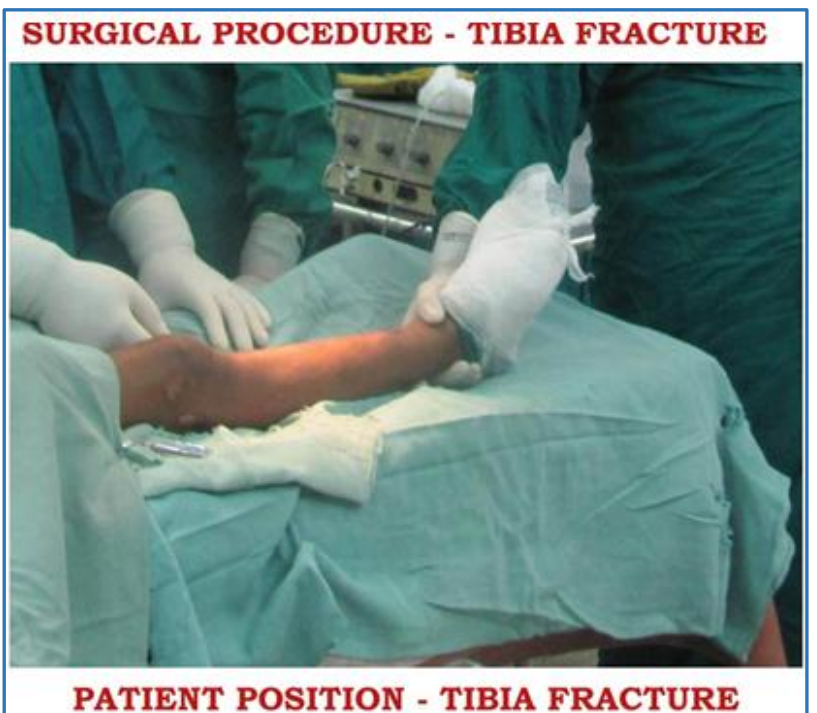

Fig. 5: Patient Positioning - Tibia Fracture

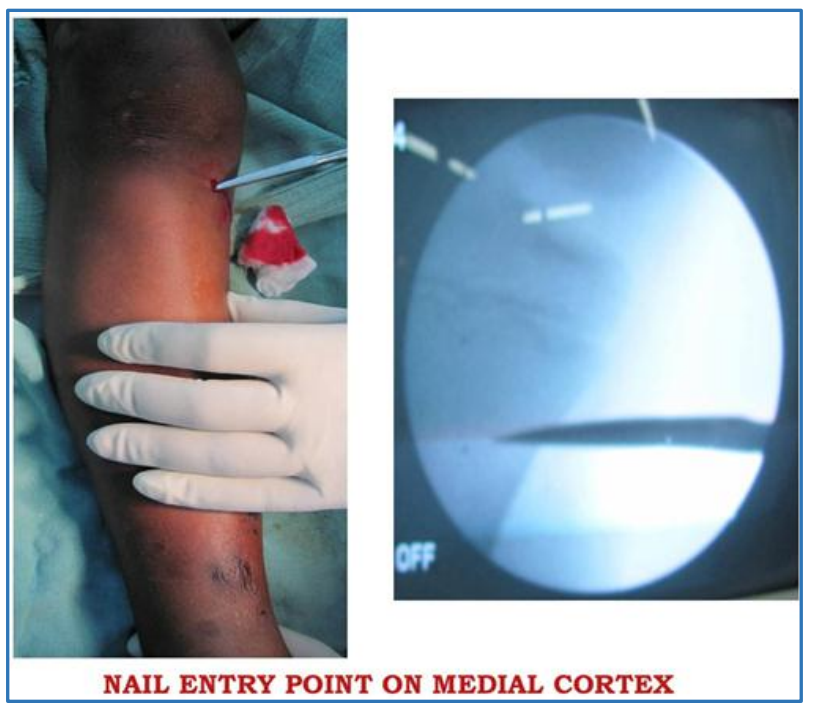

Fig. 6: Nail Entry Point - Medial Aspect of Tibia

\section{Tibia Fracture}

For Tibial shaft fractures, the entry hole is made on lateral cortex from 1.5 to $2 \mathrm{~cm}$ distal to proximal tibial physis in the midpoint of the anteroposterior dimension starting perpendicular to the epiphysis by using a curved bone awl. The bone awl is first directed at an angle of $90^{\circ}$. Then, hole is extended caudal to elongate the hole in 45 degrees angulation. After the cortex perforated, continue inserting at an angle of $45^{\circ}-60^{\circ}$.
Once the nail tips are in their final position, the end of each nail is cut leaving $1-2 \mathrm{~cm}$ protruding from the cortex. The extraosseous portion of the nail should be bent slightly away from the bone.

\section{Postoperative Care and Rehabilitation}

Immediately after surgery, limb was kept over the pillow. The patient was placed in a short leg, non-weight-bearing cast applied in comminuted fracture after surgery. Gentle knee, ankle mobilisation and also quadriceps strengthening exercises were initiated once the pain decreased. Radiographs were evaluated for alignment, callus formation and change in nail position. At the beginning of the third week, partial weight bearing was allowed. After the appearance of calcified external callus, full weight bearing was allowed. The nails were removed after clinical and radiographic fracture unions confirmed, which usually took about 6-8 months.

\section{OBSERVATIONS AND RESULTS}

In our study, 20 patients with diaphyseal fractures of femur and tibia were treated with Titanium Elastic Intramedullary Nailing. More number of patients were in the age group of 12 15 years in femur fracture $(50 \%)$ and tibia fractures (40\%). Second peak occurs in the age group of 5 to 8 years in both fractures.

\section{Age Incidence}

This study was done to find out the age incidence in our Indian set up and to know the type of fracture incidence and outcome as different age groups with response to fracture healing. More number of patients were in the age group of 12 15 years in femur fracture $(50 \%)$ and tibia fractures $(40 \%)$. Second peak occurs in the age group of 5 to 8 years in both fractures.

Table 1: Age Incidence of Long Bone Fractures

\begin{tabular}{|c|c|c|c|c|c|}
\hline $\begin{array}{c}\text { Age in } \\
\text { Years }\end{array}$ & $\begin{array}{c}\text { No. of } \\
\text { Patients }\end{array}$ & $\begin{array}{c}\text { Femur } \\
\text { Fracture }\end{array}$ & $\mathbf{\%}$ & $\begin{array}{c}\text { Tibia } \\
\text { Fracture }\end{array}$ & $\%$ \\
\hline $5-8$ yrs. & 7 & 3 & 30 & 4 & 40 \\
\hline $\begin{array}{c}9-11 \\
\text { yrs. }\end{array}$ & 4 & 2 & 20 & 2 & 20 \\
\hline $\begin{array}{c}12-15 \\
\text { yrs. }\end{array}$ & 9 & 5 & 50 & 4 & 40 \\
\hline
\end{tabular}

\section{Sex Incidence}

Among 20 children, male children (80\%) were predominant with male-to-female ratio 4:1.

Table 2: Gender Incidence of Long Bone Fractures

\begin{tabular}{|c|c|c|c|c|c|}
\hline & $\begin{array}{c}\text { No. of } \\
\text { Cases }\end{array}$ & $\begin{array}{c}\text { Femur } \\
\text { Fracture }\end{array}$ & $\mathbf{\%}$ & $\begin{array}{c}\text { Tibia } \\
\text { Fracture }\end{array}$ & $\mathbf{\%}$ \\
\hline Male & 16 & 6 & 60 & 10 & 10 \\
\hline Female & 4 & 4 & 40 & - & 0 \\
\hline
\end{tabular}

In our study, the majority of the cases were transverse fractures $(80 \%)$. Simple transverse fracture was the most common pattern of fracture tibia in our study. The average time to radiographical union for femur were 10.5 weeks (range from 8 to 12 weeks). The union was achieved in one patient at 12 weeks with comminuted fracture. Most of the fractures united at about 8.8 weeks. 
The nail diameters used in our series were $2.5 \mathrm{~mm}$ in 11 patients, $3 \mathrm{~mm}$ in 7 patients and $3.5 \mathrm{~mm}$ in 2 patients.

In general, nail removal was performed after 6 to 8 months. All children had normal range of knee and ankle motion.

Flynn Titanium Elastic Nailing Scoring System for the outcome of ESIN in a fractured femur is shown in Table.

\begin{tabular}{|c|c|c|c|}
\hline & Excellent & Satisfactory & Poor \\
\hline $\begin{array}{c}\text { Limb length in } \\
\text { equality }\end{array}$ & $<1 \mathrm{cms}$. & $<2 \mathrm{cms}$. & $>2 \mathrm{cms}$. \\
\hline Malalignment & $\begin{array}{c}<5 \\
\text { degrees }\end{array}$ & $<10$ degrees & $>10$ degrees \\
\hline Pain & Absent & Absent & Present \\
\hline Complication & Absent & Mild & $\begin{array}{c}\text { Major } \\
\text { complication } \\
\text { and/or } \\
\text { extended } \\
\text { period for } \\
\text { resolvable } \\
\text { morbidity }\end{array}$ \\
\hline \multicolumn{2}{|c|}{ Table 3: Flynn Titanium Elastic Nail Scoring System } \\
\hline
\end{tabular}

\begin{tabular}{|c|c|c|}
\hline Result & Femur & Tibia \\
\hline Excellent & 8 & 9 \\
\hline Satisfactory & 1 & 1 \\
\hline Poor & 1 & 0 \\
\hline Total & $\mathbf{1 0}$ & $\mathbf{1 0}$ \\
\hline Table 4: Flynn Scoring in Our Study \\
\hline
\end{tabular}

In our study, out of 10 patients with shaft of femur fractures, 8 patients got excellent result, one patient got satisfactory result as he had $1 \mathrm{~cm}$ shortening and nail protrusion. But, one patient got poor result as he had 10 degree of varus angulation, knee pain and $1 \mathrm{~cm}$ shortening.

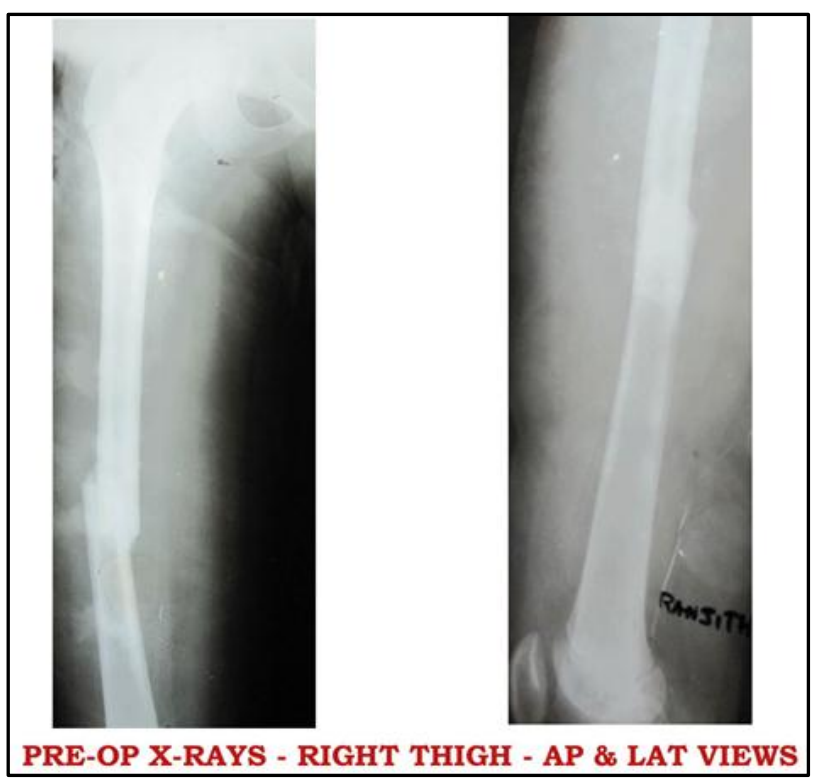

Fig. 7: Preop X-Ray AP
Fig. 8: Preop Lateral

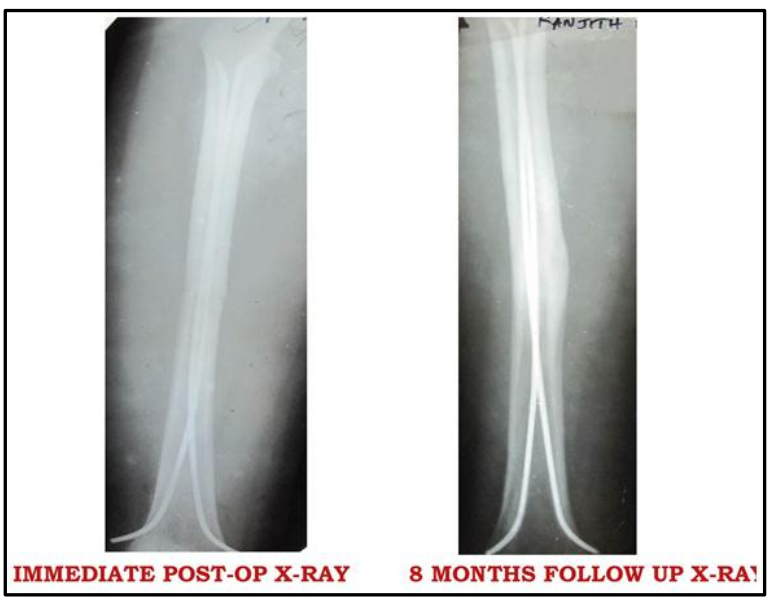

Fig. 9: Immediate Postop Fig. 10: Union - 8 months

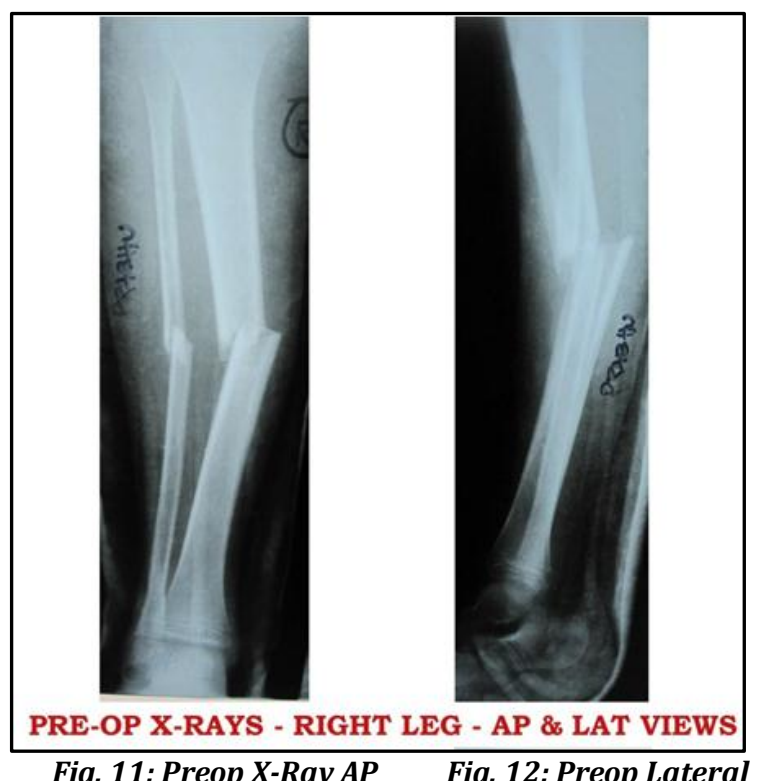

Fig. 11: Preop $X$-Ray AP Fig. 12: Preop Lateral

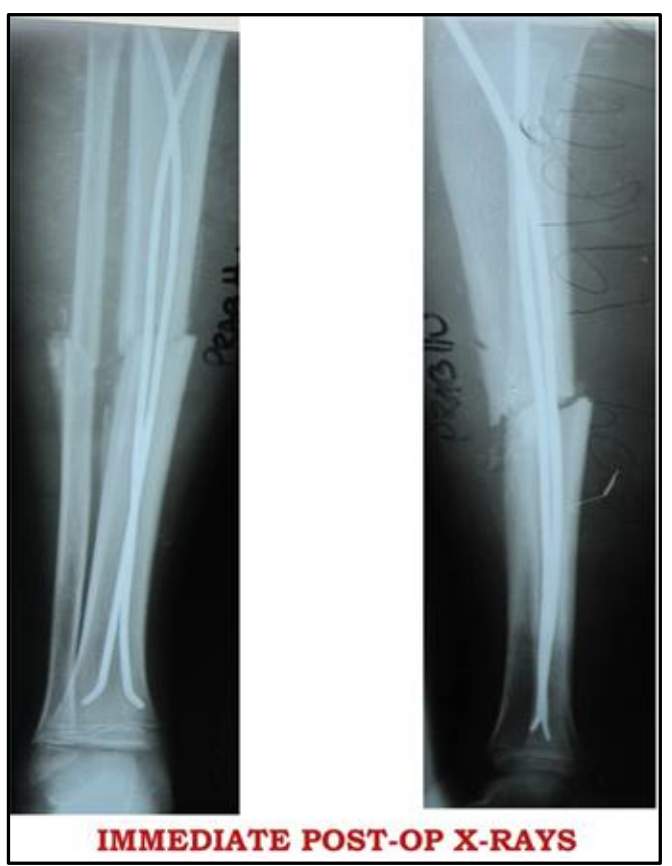

Fig. 13: Immed Postop AP Fig. 14: Immed Postop Lat 
Out of 10 patients with fracture shaft of tibia, 9 patients had excellent results. One patient had satisfactory result due to 6 degrees of varus angulation and $0.5 \mathrm{~cm}$ shortening.

Out of 20 patients, 7 cases of femur fractures and 8 cases of tibia fractures, nails were removed after complete union of fracture site clinically and radiologically. The nails were removed by opening the nail entry site.

\section{DISCUSSION}

The management of femoral and tibial fractures in children is controversial.

Paediatric femur and tibia diaphyseal fractures are treated by various methods such as immediate spica cast, traction, traction followed by spica cast, long leg cast, internal fixation with plate osteosynthesis, external fixator application, flexible intramedullary nailing and locking rigid intramedullary nail fixation.

In paediatric patients, it is also important to consider the additional home care required for a patient, missed school and time off from work required by one or both parents to care for the paediatric patient. The frequency of surgical management of paediatric femur and tibia diaphyseal fractures has increased in recent years because of the advantages of early mobilisation, easy nursing care, early rehabilitation and fast return to schools.

External fixator provides early mobilisation, but it is associated with increased risk of pin track infection, malunion and takes longer time to allow full weight bearing. It is usually reserved for open and severely comminuted fracture. ${ }^{10,11}$

Open reduction and plate osteosynthesis is associated with large exposure, longer period of immobilisation, increased risk of infection, plate breakage and stress riser effect leading to increased chance of refracture through one of the screw holes after plate removal.12,13

Interlocking nail is ideal choice for skeletally mature children. Avascular necrosis of femoral head and physeal injuries were associated complications with interlocking nail when used in skeletally immature children. ${ }^{14}$

In children, using ELASTIC STABLE INTRAMEDULLARY NAILING is technically easier than using rigid nail. The canal diameter is a restricting factor in the use of Ender nails and also, Enders nails are not elastic and flexible enough for paediatric fractures as stated by Ligier et al. ${ }^{7}$

Several authors have reported satisfactory results with the use of elastic nails in paediatric femoral and tibial fractures. Union occurs readily and joint motion is preserved with only a few, mostly minor complications. The current study compares favourably with these reports.

KC Saikia et al ${ }^{15}$ stated that elasticity of titanium elastic nail allows micro motion at fracture site, which enhances callus formation and TENS is best suited for paediatric fractures.

The most common complication in treating femoral fractures with ESIN is limb length discrepancy. In our series, 1 case of femur fracture had less than $1 \mathrm{~cm}$ shortening and two cases had more than $1 \mathrm{~cm}$ of shortening.

Malunion is another complication in femur fracture treated with ESIN. In our study, one patient showed 10 degrees varus angulation. Limb length discrepancy and malunion did not alter the functional outcome of the patients in our study.
We have analysed rotational deformity clinically by looking in-toeing and out-toeing gait. In our study, no one had rotational deformities.

In our series, union of fracture site progressed satisfactorily in all 10 cases. All fractures united between 8 to 12 weeks. Average union time was 10.5 weeks.

\section{TIBIA FRACTURE}

Limb length discrepancy is one of the complications in tibia fractures treated with TENS. In our series, 1 case had $1.5 \mathrm{~cm}$ of shortening and another one case had less than $1 \mathrm{~cm}$ shortening.

Six degrees of varus angulation was observed in one patient. It did not give problem for patient.

No case of rotational deformity was noted in tibia fractures treated with titanium elastic nailing.

Nail protrusion from the entry site is commonest cause of pain and stiffness in the knee.

From a cost-analysis standpoint, some studies suggested that the overall cost was significantly lower when ESIN was used compared with traction followed by spica casting. Another study showed that patients treated with ESIN were able to ambulate sooner after surgery and returned to school earlier than patients treated with traction followed by spica casting. We have had a similar experience in our own practice in terms of early ambulation and early return to school.

The overall results showed $80 \%$ excellent, $10 \%$ satisfactory and $10 \%$ poor results.

In our study, 12 cases had nail protrusion and soft tissue irritation around the knee joint. Out of 20 patients, one patient had superficial infection, which was treated with appropriate antibiotics. No refracture was observed in our study after nail removal in 7 cases.

\section{CONCLUSION}

Our study has shown that ESIN has minimal complications, easier postoperative maintenance and excellent outcome when compared to other methods of treatment in treating lower limb fractures in skeletally immature patients 5-15 years of age and enables early ambulation with good functional results. It is technically simple and reliable procedure. Excellent results were achieved with it in terms of union and full weight bearing. Preoperative planning, intraoperative details and technical execution as well as appropriate postoperative care and followup are all important in predicting good outcome.

Parents should be advised that minor complications are not uncommon.

\section{REFERENCES}

1. Fry K, Hoffer MM, Brink J. Femoral shaft fractures in brain-injured children. J Trauma 1976;16(5):371-3.

2. Hedlund $\mathrm{R}$, Lindgren $\mathrm{U}$. The incidence of femoral shaft fractures in children and adolescents. J Pediatr Orthop 1986;6(1):47-50.

3. Landin LA. Fracture patterns in children. Analysis of 8,682 fractures with special reference to incidence, etiology and secular changes in a Swedish urban population 1950-1979. Acta Orthop Scand Suppl 1983;202:1-109.

4. Shannak AO. Tibial fractures in children: follow-up study. J Pediatr Orthop 1988;8(3):306-10. 
5. Steinert VV, Bennek J. Unterschenkelfrakturen im Kindesalter. Zentralbl Chir 1966;91:1387-92.

6. Weber BG, Brunner C, Freuner F. Treatment of fractures in children and adolescents. Springer 1980:319-23.

7. Ligier JN, Metaizeau JP, Prevot J, et al. Elastic stable intramedullary nailing of femoral shaft fractures in children. J Bone Joint Surg Br 1988;70(1):74-7.

8. Dietz $\mathrm{HG}$, Schmittenbecher $\mathrm{P}$, Illing $\mathrm{P}$. Intramedulläre Osteosynthese im. Wachstumsalter Urban and Schwarzenberg München-Wien Baltimore 1997:135-68.

9. Dietz HG, Schmittenbecher P, Slongo T, et al. Elastic Stable Intramedullary Nailing (ESIN) in Children. AO Manual of Fracture Management. New York: Thieme 2006.

10. Aronson J, Tursky EA. External fixation of femur fractures in children. J Pediatr Orthop 1992;12(2):157-63.
11. Krettek C, Haas N, Walker J, et al. Treatment of femoral shaft fractures in children by external fixation. Injury 1991;22(4):263-6.

12. Reeves RB, Ballard RI, Hughes JL. Internal fixation versus traction and casting of adolescent femoral shaft fractures. J Pediatr Orthop 1990;10(5):592-5.

13. Ward WT, Levy J, Kaye A. Compression plating for child and adolescent femur fractures. J Pediatr Orthop 1992;12(5):626-32.

14. Beaty JH, Austin SM, Warner WC, et al. Interlocking intramedullary nailing of femoral-shaft fractures in adolescents: preliminary results and complications. J Pediatr Orthop 1994;14(2):178-83.

15. Saikia KC, Bhuyan SK, Bhattacharya TD, et al. Titanium elastic nailing in femoral diaphyseal fractures of children in 6-16 years of age. IJO 2007;41(4):381-85. 